\title{
Slide Malaria Positif pada Murid SDN 45 Pulau Karam Kecamatan Koto XI Tarusan Kabupaten Pesisir Selatan
}

\author{
Fitria Ramanda ${ }^{1}$, Nurhayati $^{2}$, Endrinaldi ${ }^{3}$
}

\begin{abstract}
Abstrak
Penyakit malaria hingga saat ini masih merupakan masalah kesehatan di Indonesia. Secara epidemiologi Indonesia merupakan daerah endemis mayor malaria di Asia tenggara. Kabupaten Pesisir Selatan adalah salah satu daerah endemis malaria di Sumatera Barat. Tujuan penelitian ini adalah untuk mengetahui frekuensi parasit malaria berdasarkan umur, kenis kelamin dan angka hitung parasitnya (Parasite Count). Telah dilakukan penelitian pada murid SD 45 Pulau Karam dengan jenis penelitian deskriptif. Data diperoleh dengan pemeriksaan mikroskopis sediaan darah tebal dan tipis yang dipulas dengan pewarnaan Giemsa. Hasil penelitian terhadap 97 murid SDN 45 Pulau Karam di dapatkan angka parasit sebanyak $28 \%$ dan spesies Plasmodium yang ditemukan seluruhnya merupakan Plasmodium falsiparum. Bedasarkan golongan umur, distribusi frekuensi parasit malaria tertinggi ditemukan pada umur $<10$ tahun yaitu 59\% dan berdasarkan jenis kelamin, di dapatkan persentase terbesar pada anak laki-laki yaitu sebesar $78 \%$. Parasite Count pada slide darah yang positif parasit malaria yang tertinggi persenan adalah yang $<250 / \mathrm{mm}^{3}$ yaitu sebanyak $96 \%$.
\end{abstract}

Kata kunci: slide darah tebal dan tipis, Parasite Rate, Plasmodium falsiparum, Parasite Count.

\begin{abstract}
Malaria is still a health problem in Indonesia. Indonesia is a major malaria endemic areas in Southeast Asia. District Pesisir Selatan is one of the endemic areas in West Sumatera. The objective of this study was to find the frequency of malaria parasite based on species of malaria parasite, age, gendre and Parasite Count, a study was done on elementary student in SDN 45 Pulau Karam. This research was descriptive. Data obtained by microscopic examination of thick and thin blood preparations were daubed with Giemsa staining. The study of 97 students of SDN 45 Pulau Karam in getting the numbers as much as $28 \%$ and the Plasmodium species is found throughout Plasmodium falciparum. Based on the age group, the highest frequency distribution of the malaria parasite was found at age $<10$ years is $59 \%$ and base on gendre, in getting the largest percentage of boys is equal to $78 \%$. Parasite Count on positive blood preparations of the highest malaria parasite gratuities are $<250 / \mathrm{mm}^{3}$ as many as $96 \%$.
\end{abstract}

Keywords: thick and thin blood preparations, Parasite Rate, Plasmodium falciparum, Parasite Count.

Affiliasi penulis: 1. Pendidikan Dokter FK UNAND (Fakutas Kedokteran Universitas Andalas Padang), 2. Bagian Parasitologi FK UNAND, 3. Bagian Kimia Kedokteran FK UNAND

Korespondensi: Fitria Ramanda, E-mail: f3_shofwah@yahoo.com, Telp: 085263825602

\section{PENDAHULUAN}

Malaria termasuk penyakit yang sekarang ini masih menjadi masalah kesehatan masyarakat, baik di Indonesia, mupun di dunia. Malaria dapat menjadi penyebab kematian, terutama pada kelompok resiko tinggi yaitu bayi, anak balita, ibu hamil, selain itu malaria secara langsung menyebabkan anemia dan dapat menurunkan produktifitas kerja. Dari data epidemiologi, anak-anak memiliki resiko yang tinggi untuk terkena malaria. Anak-anak lebih beresiko terhadap malaria dibandingkan orang dewasa. ${ }^{1}$

Diagnosis malaria ditegakkan dengan pemeriksaaan slide darah tepi (slide darah tebal dan tipis). Pasien positif terkena malaria jika ditemukan parasit malaria (Plasmodium $s p$ ) pada slide darah tersebut. Pemeriksaan darah tepi merupakan gold standard diagnosisnya, karena dengan pemeriksaan 
slide darah dapat dilihat kepadatan dan jenis parasit malaria. $^{2}$ Kepadatan parasit malaria berhubungan dengan gejala klinis yang ditimbulkan. ${ }^{3}$

Pada daerah endemis malaria, individu yang tinggal di daerah tersebut, baik orang dewasa, maupun anak-anak, akan memiliki kekebalan terhadap malaria. Kekebalan ini menyebabkan individu tersebut tidak mengalami gejala klinis yang berarti. Begitu juga pada anak-anak. ${ }^{4}$ Kekebalan terhadap malaria ini didapatkan karena frekuensi yang sering terhadap paparan nyamuk vektor malaria sehingga dapat ditemui parasit di dalam darahnya tanpa ada gejala klinis malaria. Perlu dilakukan pemeriksaan berkala pada daerah endemis untuk menekan angka penularan malaria. Dari pemeriksaan berkala akan didapatkan data Parasite Rate (angka parasit), yaitu berapa persen masyarakat masyarakat disuatu daerah yang di dalamnya darahnya mengandung parasit malaria. Jika pada pemeriksaan slide darah tepi ditemukan parasit malaria fase gametosit akan menyebabkan penularan pada individu lain, karena apabila nyamuk menghisap darah yang ada gametositnya akan terjadi fase seksual parasit di dalam tubuh nyamuk vektor. ${ }^{5}$

Secara global penyakit malaria ini sudah mendapat perhatian khusus untuk penanganannya, melalui organisasi dunia yang bergerak dibidang kesehatan, WHO (World Health Organization) di bawah naungan PBB, telah mengambil langkah dengan mengadakan program khusus untuk penanganan malaria, yaitu GMP (Global Malaria Programme). ${ }^{6}$

Upaya penanggulangan penyakit malaria di Indonesia sejak tahun 2007 dapat dipantau dengan menggunakan indikator Annual Parasite Incidence (API) melalui pemeriksaan slide darah tepi. Pada tahun 2007 dikeluarkan kebijakan yang mensyaratkan bahwa setiap kasus malaria harus dibuktikan dengan hasil pemeriksaan slide darah dan semua kasus positif harus diobati dengan pengobatan kombinasi berbasis artemisinin atau ACT (Artemisinin-based Combination Therapies). ${ }^{1}$

Pencegahan malaria ini juga dilakukan dengan pembagian kelambu berinsektisida atau ITN (Insectiside-Treated Bednets), namun pencegahan terhadap malaria di Indonesia masih kurang optimal dilaksanakan. ${ }^{7}$

Penyebaran malaria di dunia sangat luas, yaitu pada negara yang beriklim tropis dan subtropis. Pada tahun 2010, dilaporkan kejadian malaria sebanyak 4,3 juta kasus dengan 2,4 juta kasus dibuktikan dengan secara parasitologi. Malaria banyak menyebabkan kematian, dilaporkan angka kematian di Asia Tenggara akibat malaria sebanyak 2426, mayoritasnya (93\%) di tiga negara, yaitu India, Indonesia, dan Myanmar. ${ }^{8}$

Kejadian Luar Biasa (KLB) di Indonesia dilaporkan terjadi di beberapa pulau. Dari data yang didapatkan, KLB terjadi di pulau Jawa (Jawa Tengah, Jawa Timur, dan Banten), Kalimantan (Kalimantan Selatan), Sulawesi (Sulawesi Barat), NAD, dan Sumatera (Sumatera Barat, Lampung). ${ }^{1}$

Di wilayah Sumatera Barat, pada tahun 2010 dari 4701 slide darah yang diperiksa ada 1104 slide yang positif malaria (ditemukan parasit malaria pada slide darah). Kabupaten dengan angka AMI (Annual Malaria Incidence) berdasarkan gejala klinis malaria pada pasien, yang cukup tinggi yaitu Kabuaten Kepulauan Mentawai, Pasaman Barat, Pesisir Selatan, Sawahlunto, Sijunjung, dan Solok Selatan. ${ }^{9}$

Berdasarkan data Dinkes, Kabupaten Pesisir Selatan termasuk daerah endemis malaria. Dilihat dari kondisi geografisnya, daerah Kabupaten Pesisir Selatan terdiri dari pantai yang mempunyai banyak genangan air payau (lagun), daerah pegunungan (banyak hutan), dan daerah pertanian (banyak rawa dan sawah), kondisi seperti ini sangat cocok sebagai tempat perindukan nyamuk Anopheles sebagai vektor penyakit malaria. ${ }^{9}$

Jumlah kasus malaria di Kabupaten Pesisir Selatan dari tahun 1999 s/d 2006 cenderung menurun. Namun pada tahun 2007 jumlah kasus kembali meningkat. Pada tahun 2010, jumlah kasus malaria klinis aalah 955 kasus (angka Annual Malaria Incidence / AMI adalah 2,2 per 1000 penduduk). Pada tahun 2010 kasus malaria tertinggi ditemukan di Puskesmas Pasar Baru (AMI = 10,9\%) dan Puskesmas Tarusan (AMI = 7,6\%). ${ }^{9}$

Salah satu dusun endemis malaria yang berada di wilayah kerja Puskesmas Tarusan di Kecamatan 
Koto XI Tarusan adalah Dusun Pulau Karam. Dusun ini merupakan daerah pantai dan persawahan.

Informasi yang didapatkan dari Kepala

Puskesmas Tarusan, selama ini pemeriksaan malaria yang khusus untuk anak-anak tidak dilakukan. Pemeriksaan sering dilakukan pada masyarakat umum saja.

Pemeriksaan slide darah tepi pada anak-anak di daerah endemis malaria perlu dilakukan untuk menatalaksana dengan segera gejala yang timbul akibat malaria, karena itu perlu dilakukan penelitian tentang slide malaria positif pada murid SDN 45 Pulau Karam di Tarusan Kabupaten Pesisir Selatan.

\section{METODE}

Jenis penelitian ini adalah deskriptif. Pengambilan slide darah yang diteliti dilakukan pada tanggal 7-14 Maret 2013 di SDN 45 Pulau Karam Tarusan. Pemeriksaan slide darah dilakukan di laboratorium Parasitologi Fakultas Kedokteran Universitas Andalas. Penelitian ini dilakukan mulai dari bulan Januari-Maret 2013. Populasi dalam penelitian ini adalah semua murid SDN 45 Pulau Karam di Tarusan Kabupaten Pesisir Selatan. Sampel penelitian diambil dari populasi yang merupakan semua murid SDN 45 Pulau Karam yang memenuhi kriteria inklusi dan eksklusi. Kriteria inklusi yaitu bersedia dan disetujui oleh orangtua menjadi subjek penelitian. Sementara murid yang menjalani pengobatan malaria dalam satu bulan terakhir dan slide darah yang rusak ketika sampai di laboratorium merupakan kriteria pada penelitian ini.

\section{HASIL}

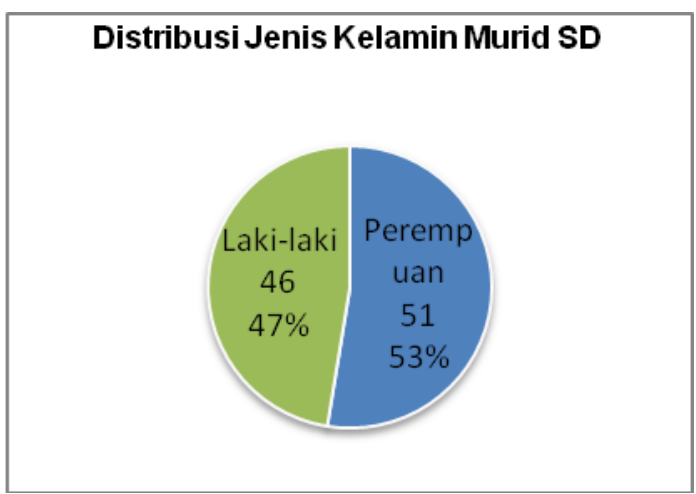

Gambar 1. Distribusi jenis kelamin murid SDN 45 Pulau Karam
Dari 101 murid, 4 murid masuk ke dalam kriteria eksklusi, sehingga jumlah murid yang masuk ke dalam kriteria inklusi sebanyak 97 orang. Dari 97 murid tersebut, jumlah yang perempuan 51 orang, sedangkan yang laki-laki 46 orang.

\section{Distribusi Bedasarkan Kelompok Umur Murid}

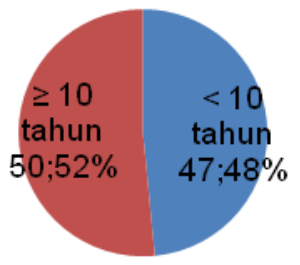

Gambar 2. Distribusi berdasarkan kelompok umur Murid SDN 45 Pulau Karam

Rentangan umur murid-murid tersebut adalah 6-13 tahun. Bila dikelompokkan berdasarkan umur yang brumur $<10$ tahun sebanyak 47 orang, sedangkan yang berumur $\geq 10$ tahun sebanyak 50 orang.

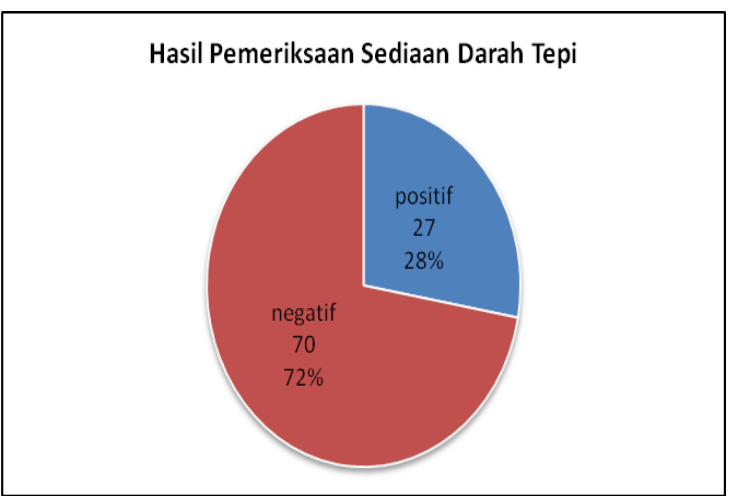

Gambar 3. Hasil pemeriksaan slide darah murid SDN 45 Pulau Karam

Pada murid SDN 45 Pulau Karam ini dilakukan pengambilan darah tepi, kemudian dibuat slide darah tebal dan tipis. Seluruh slide darah tebal dan tipis dipulas dengan Giemsa dan diperiksa di laboratorium Parasitologi Fakultas Kedokteran Universitas Andalas. Dari pemeriksaan didapatkan 27 orang anak yang positif terdapat parasit malaria.

Angka parasit (Parasite Rate) pada anak SDN 45 Pulau Karam tersebut adalah:10 
Parasite Rate $(\mathrm{PR})=$ Jumlah sediaan darah positif $\times 100 \%$ Jumlah SD yang diperiksa

$$
=\underline{27} \times 100 \%
$$

97

$=27,84 \%=28 \%$

Dari 97 murid yang diperiksa slide darah tepinya, didapatkan Parasite Rate sebanyak $28 \%$.

Tabel 1. Distribusi parasit malaria yang ditemukan pada murid SDN 45 Pulau Karam berdasarkan spesies

\begin{tabular}{lcc}
\hline \multirow{2}{*}{ Spesies } & \multicolumn{2}{c}{$\begin{array}{c}\text { Sedian darah yang positif } \\
\text { parasit malaria }\end{array}$} \\
\cline { 2 - 3 } & $\begin{array}{c}\text { Jumlah Slide } \\
\text { Positif }\end{array}$ & $\%$ \\
\hline P.falsiparum & 27 & 100 \\
P.vivax & - & - \\
P.malariae & - & - \\
P.ovale & - & - \\
P.knowlesi & - & - \\
\hline Jumlah & 27 & 100 \\
\hline
\end{tabular}

Spesies Plasmodium dari 27 orang positif parasit malaria dapat dilihat pada Tabel 1. Pada Tabel 1 dapat dilihat bahwa hanya spesies P.falsiparum yang ditemukan pada seluruh slide darah tepi. Tidak ditemukan P.vivax, P.malariae, P.ovale, dan $P$.knowlesi pada penelitian ini.

Tabel 2. Distribusi frekuensi parasit malaria pada murid SDN Pulau Karam berdasarkan kelompok umur

\begin{tabular}{ccc}
\hline Umur (th) & $\begin{array}{c}\text { Jumlah Murid yang } \\
\text { Positif }\end{array}$ & $\begin{array}{c}\text { Persentase } \\
\text { positif (\%) }\end{array}$ \\
\hline$<10$ & 16 & 59 \\
$\geq 10$ & 11 & 41 \\
Jumlah & 27 & 100 \\
\hline
\end{tabular}

Pada hasil yang diperoleh dari table 2 terlihat bahwa, jumlah yang positif parasit malaria lebih tinggi pada kelompok umur $<10$ tahun (59\%) dibandingkan dengan kelompok umur $\geq 10$ tahun $(41 \%)$.
Tabel 3. Distribusi parasit malaria murid SDN 45 Pulau Karam berdasarkan jenis kelamin

\begin{tabular}{lcc}
\hline \multicolumn{1}{c}{ Jenis Kelamin } & $\begin{array}{c}\text { Jumlah Murid } \\
\text { yang Positif }\end{array}$ & $\begin{array}{c}\text { Persentase } \\
(\%)\end{array}$ \\
\hline Perempuan & 6 & $22 \%$ \\
Laki-laki & 21 & $78 \%$ \\
\hline Jumlah & 27 & $100 \%$
\end{tabular}

Tabel 3 dapat dilihat bahwa, jumlah positif parasit malaria lebih tinggi pada laki-laki (78\%) dibanding perempuan (22\%).

Hitung parasit (Parasite Count) slide darah yang positif parasit malaria berkisar antara 120$280 / \mathrm{mm}^{3}$. Parasite Count yang kurang dari 250/ $\mathrm{mm}^{3}$ sebanyak 26 (96\%), Parasite Count antara 2501000/mm³ sebanyak 1 (4\%). Tidak ditemukan Parasite Count yang lebih dari $1000 / \mathrm{mm}^{3}$, dapat dilihat pada tabel 4.

Tabel 4. Parasite Count pada slide darah tepi yang positif parasit malaria

\begin{tabular}{ccc}
\hline $\begin{array}{c}\text { Hitung parasit } \\
\left(/ \mathrm{mm}^{3}\right)\end{array}$ & $\begin{array}{c}\text { Jumlah Slide } \\
\text { Positif }\end{array}$ & $\begin{array}{c}\text { Persentase } \\
(\%)\end{array}$ \\
\hline$<250$ & 26 & 96 \\
$250-1000$ & 1 & 4 \\
$>1000$ & 0 & 0 \\
Jumlah & 27 & 100 \\
\hline
\end{tabular}

\section{PEMBAHASAN}

Berdasarkan hasil penelitian pada murid SDN 45 Pulau Karam Kecamatan Koto XI Tarusan Kabupaten Pesisir Selatan, didapatkan angka parasit (Parasite Rate) 28\%. Hasil yang diperoleh lebih rendah bila dibandingkan dengan hasil penelitian yang dilakukan oleh Roni pada tahun 2003 di SD Desa Apiapi Kanagarian Pasar Baru Kecamatan Bayang Kabupaten Pesisir Selatan, angka parasit yang didapatkan sebesar $83,16 \% .^{10} \mathrm{Hal}$ ini sesuai dengan data Dinkes Pesisir Selatan yaitu angka kejadian malaria lebih tinggi di Puskesmas Pasar Baru dibandingkan dengan di Puskesmas Tarusan. ${ }^{9}$

Pada penelitian ini dari seluruh slide darah tebal dan tipis yang diperiksa, terdapat 27 slide darah 
yang positif terdapat parasit malaria, didapatkan $100 \%$ merupakan Plasmodium fasciparum, tidak ditemukan Plasmodium vivax, Plasmodium malariae, Plasmodium ovale, dan Plasmodium knowlesi. Hal ini sesuai dengan data dari Riskesdas (Riset Kesehatan Dasar) tahun 2010 yaitu Plasmodium yang banyak ditemukan di Indonesia adalah Plasmodium falsiparum (86,4\%). ${ }^{1}$ Pada penelitian yang dilakukan oleh Permana pada tahun 2003 di SD Desa Api-api Kanagarian Pasar Baru Kecamatan Bayang Kabupaten Pesisir Selatan, spesies Plasmodium yang ditemukan seluruhnya adalah Plasmodium falsiparum. ${ }^{11}$

Dari 27 slide darah yang diperiksa, jumlah yang positif parasit malaria lebih tinggi pada umur $<10$ tahun (59\%) dibandingkan dengan anak yang berumur $\geq 10$ tahun (41\%). Didukung oleh data Kementrian Kesehatan Republik Indonesia, didapatkan bahwa anak umur 5-9 tahun memiliki poin prevalensi malaria tertinggi. ${ }^{1}$ Didukung oleh penelitian Mooduto pada tahun 2012 di Puskesmas Bongomeme Kecamatan Bongomeme Kabupaten Gorontalo, yang menyatakan bahwa angka kejadian malaria pada kelompok umur 5$9(9,1 \%)$ lebih tinggi di bandingkan dengan kelompok umur $10-14$ (6,8\%). ${ }^{12}$ Hal ini behubungan dengan perkembangan imunitas tubuh pada anak, semakin bertambah umur anak, semakin tinggi imunitas tubuhnya. Pada daerah endemis malaria, imunitas terhadap malaria akan berkembang dengan bertambahnya umur. ${ }^{13}$

Berdasarkan jenis kelamin, pada penelitian ini di dapatkan persentase positif malaria lebih tinggi pada murid laki-laki (78\%) dibandingkan murid perempuan (22\%). Didukung oleh data Kemenkes RI, didapatkan data bahwa laki-laki lebih banyak mengalami malaria dibandingkan dengan wanita. ${ }^{1}$ Pada penelitian yang dilakukan oleh Muriuki et al pada tahun 2012 di daerah korban tsunami Aceh, laki-laki lebih banyak yang terkena malaria dibandingkan dengan wanita, hal ini berhubungan dengan paparan oleh nyamuk vektor malaria. ${ }^{14}$

Angka dari seluruh sediaan darah yang positif parasit malaria dihitung Parasite Count-nya, didapatkan angka hitung parasit yang kurang dari 250/mm $\mathrm{mm}^{3}$ sebanyak $96 \%$, Parasite Count antara 2501000/mm³ sebanyak 4\%. Untuk Parasite Count yang lebih dari 1000/mm³ tidak ditemukan. Didukung oleh data dari WHO, menurut penelitian yang dilakukan di daerah endemis malaria, pada anak berumur $<5$ tahun dan 1-10 tahun didapatkan Parasite Count antara $200-500 / \mathrm{mm}^{3} .15$

Pada daerah endemis, penduduk setempat akan terus terpapar oleh parasit malaria, sehingga akan terbentuk imunitas terhadap malaria, imunitas ini bergantung pada frekuensi terpapar oleh nyamuk vektor malaria dan infeksi oleh berbagai jenis strain Plasmodium. ${ }^{16}$ Imunitas terbentuk pada individu yang di dalam darahnya terdapat parasit malaria. ${ }^{17}$ Karena itu pada daerah endemis dapat ditemukan orang dengan parasitemia (ada parasit malaria di dalam darahnya), tetapi tidak menimbulkan gejala klinis (asimptomatis). ${ }^{18}$ Kondisi tanpa gejala klinis ini menyebabkan meningkatnya angka morbiditas, karena akan berakibat pada penurunan berat badan, anemia, sclera pucat, dan hepatosplenomegali. Hal tersebut disebabkan karena pendeknya umur sel darah merah akibat ada parasit di dalamnya. Pada anak-anak kondisi tersebut dapat menyebabkan terlambatnya pertumbuhan dan perkembangannya. ${ }^{19}$

Pada penelitian ini, murid yang positif malaria tidak menunjukkan gejala klinis malaria. Dalam penelitian yang dolakukan oleh Dimitri pada tahun 1999 dipaparkan bahwa angka Parasite Count berhubungan dengan gejala klinis yang timbul. Semakin rendah angka Parasite Count, maka gejala klinis yang ditimbulkan akan berkurang. Anak yang Parasite Count-nya $<1000 / \mathrm{mm}^{3}$ diperkirakan pernah memiliki riwayat gejala klinis demam dan dengan angka Parasite Count tersebut tidak ditemukan gejala klinis yang berarti. ${ }^{18,20}$ Jika ditemukan Parasite Count pada slide darah yang positif parasit malaria $\geq$ $5000 / \mathrm{mm}^{3}$ dapat dipastikan bahwa sebelumnya individu tersebut mengalami demam. ${ }^{20}$

Desa Pulau Karam merupakan daerah di Kabupaten Pesisir Selatan yang terletak di pinggir pantai, dengan rawa-rawa, daerah persawahan, dan banyak lagun (genangan air payau). Dengan kondisi topografi seperti di atas, menjadi tempat perkembang biakan yang tepat bagi nyamuk vektor malaria. ${ }^{9}$

Hasil slide darah positif parasit malaria, hanya fase tropozoit yang ditemukan. Jika ditemukan parasit malaria pada fase gametosit akan menyebabkan penularan pada individu lain, karena apabila nyamuk 
menghisap darah yang ada gametositnya akan terjadi fase seksual parasit di dalam tubuh nyamuk vektor. ${ }^{19}$

Penelitian yang dilakukan ini memiliki suatu kekurangan. Pada kuesioner tidak ditanyakan pada orangtua apakah sebelumnya pernah mengalami malaria waktu kecil, karena malaria yang telah dialami berhubungan erat dengan terbentuknya imunitas terhadap malaria pada daerah endemis. Hal ini dapat diatasi kembal dengan menghubungi orangtua murid, tetapi karena adanya kendala jarak yang jauh antara peneliti dengan daerah penelitian, data tersebut tidak dapat dikumpulkan.

\section{KESIMPULAN}

Besar angka parasit (Parasite Rate) pada murid SD 45 Pulau Karam adalah 28\%.

Spesies parasit malaria yang ditemukan adalah Plasmodium falsiparum.

Distribusi frekuensi parasit malaria berdasarkan umur, persentase tertinggi adalah pada anak dengan umur $<10$ tahun yaitu sebanyak $59 \%$.

Distribusi frekuensi malaria berdasarkan jenis kelamin, persentase tertinggi adalah pada anak lakilaki yaitu sebanyak $78 \%$.

Temuan angka hitung parasit pada slide darah yang positif parasit malaria paling tinggi adalah < $250 / \mathrm{mm}^{3}$ sebanyak $96 \%$.

\section{DAFTAR PUSTAKA}

1. Laihad FJ, Harijanto PN, Poespoprodjo JR. Epidemiologi Malaria di Indonesia. Buletin Jendela Data dan Informasi Kesehatan. Jakarta: Kementerian Kesehatan RI; 2011.

2. National Institute of Malaria Research. Guidelines for diagnostic and treatment of malaria. India: Goverment of India; 2009.

3. Harijanto PN. Malaria: epidemiologi, patogenesis, manifestasi klinis, \& penanganan. Jakarta: EGC; 2000.

4. Achtman $A H$, Bull PC, Sthephens R, Langhorne J. Longevity of the immune response and memory to blood-stage malaria infection. Dalam: Langhorne J, editor (penyunting). Immunology and Immuno pathology of Malaria. Heidelberg: Springer; 2005.hlm.73-6.
5. Harijanto PN. Malaria. Dalam: Sudoyo AW, Setiyohadi B, Alwi I, Simadibrata M, Setiati S, editor (penyunting). Buku Ajar IImu Penyakit Dalam. Jakarta: Interna Publishing; 2009.hlm.2813-25.

6. World Health Organization. About WHO: Global Malaria Programme (GMP). (diunduh 15 April 2012). Tersedia dari: URL: HYPERLINK http://www.who.int/malaria/about us/en/index.html.

7. Badan Perencanaan Pembangunan Nasional. Target 6C: Mengendalikan penyebaran \& mulai menurunkan jumlah kasus baru malaria \& penyakit utama lainnya hingga tahun 2015. Dalam: Peta Jalan Percepatan Pencapaian Tujuan Pembangunan Milenium di Indonesia. Jakarta: Kementrian Perencanaan Pembangunan Nasional; 2010.hlm.164-8.

8. World Health Organization. World malaria report: 2011. Switzerland: WHO Press; 2011.

9. Dinas Kesehatan Propinsi Sumatera Barat. Laporan kumulatif penemuan dan pengobatan malaria. Padang; 2011.

10. Kakkilaya BS, 2011. The Malaria Parasite. (diunduh 23 Februari 2013). Tersedia dari: URL: HYPERLINK http://www.malariasite.com/malaria/ MalarialParasite.htm

11. Permana R. Frekuensi malaria pada murid SD tanpa gejala klinis di Desa Api-api Kanagarian Pasar Baru Kecamatan Bayang Kabupaten Pesisir Selatan (skripsi). Padang: Universitas Andalas; 2003.

12. Mooduto PT. Karakteristik penderita malaria di wilayah kerja Puskesmas Bongomeme kecamatan Bongomeme Kabupaten Gorontalo Tahun 20092011 (skripsi). Gorontalo: Universitas Negeri Gorontalo; 2012.

13. Robinson AT. Malaria in endemic human populations clinical disease, imnunity and protection. 2001 (diunduh 1 April 2013). Tersedia dari: URL: HYPERLINK http://www.pathmicro.med. scedu/parasitology..

14. Muriuki D, Hahn S, Hexom B, Allan R. Crosssectional Survey of Malaria Prevalence in Tsunami-affected Districts of Aceh Province, Indonesia. International Journal of Emergency 
Medicine.2012; 5:11.

15. World Health Organization. Malaria elimination: a field manual for low and moderate endemic countries. Switzerland: WHO Press; 2007.

16. Kinyanjui SM. The Immunology of Malaria. Dalam (Okwa OO, eds) Malaria Parasite. Intechopen.com. 2012.

17. Bejon P. Analysis of immunity to febrile malaria in children that distinguishes immunity from lack of exposure. Infection and Immunity. 2009;77:191723.

18. Avrina R, Risniati $Y$, Siswantoro $H$, Hasugian $A R$, Tjitra E, Delima. Hubungan kepadatan parasit dengan manifestasi klinis pada malaria Plasmodium falciparum dan Plasmodium vivax. Media Litbang Kesehatan. 201; 21: 119-26.

19. Harijanto PN. Malaria. Dalam: Sudoyo AW, Setiyohadi B, Alwi I, Simadibrata M, Setiati S, editor (penyunting). Buku Ajar IImu Penyakit Dalam. Jakarta: Interna Publishing. 2009.hlm.2813-25.

20. Prybylski D, Khaliq A, Fox E, Sarwari AR, Strickland GT. Parasite density and malaria morbidity in the Pakistani Punjab. American Society of Tropical Medicine and Hygiene. 1999; 61: 791-801. 